\title{
Differential Scanning Calorimetry Fingerprints of Various Heat-Treatment Tempers of Different Aluminum Alloys
}

\author{
Zhixing Chen ${ }^{1}$, Kun Liu ${ }^{1, *}$ (D) Emad Elgallad ${ }^{1}$, Francis Breton ${ }^{2}$ and X.-Grant Chen ${ }^{1}$ \\ 1 Department of Applied Science, University of Quebec at Chicoutimi, Saguenay, QC G7H 2B1, Canada; \\ zhixing.chen1@uqac.ca (Z.C.); emad_elgallad@uqac.ca (E.E.); XGrant_Chen@uqac.ca (X.-G.C.) \\ 2 Arvida Research and Development Centre, Rio Tinto Aluminum, Saguenay, QC G7S 4K8, Canada; \\ francis.breton@riotinto.com \\ * Correspondence: kun.liu@uqac.ca; Tel.: +1-418-545-5011 (ext. 7112)
}

Received: 21 May 2020; Accepted: 5 June 2020; Published: 8 June 2020

\begin{abstract}
Heat-treatable cast and wrought aluminum alloys are widely used for structural applications in the automobile and aerospace industries. To assess and diagnose the production and quality problems related to industrial heat treatments, differential scanning calorimetry (DSC) was used as a tool in the present work to determine the thermal histories of samples that had undergone different tempers of three commonly used aluminum alloys, namely a high-pressure die-cast AlSi10Mg0.3Mn alloy, permanent-mold cast Al-Si-Cu 319 alloy, and extruded Al-Mg-Si AA6082 alloy. Various peaks detected in the DSC curves were analyzed and characterized to identify the precipitation/dissolution reactions of metastable phases, aiming to establish a "fingerprint" of each temper of the three experimental alloys. Results showed that both the number and size of exothermic peaks varied with the temper owing to distinct precipitation behaviors, providing an effective means of fingerprinting the various tempers. Meanwhile, electrical conductivity and microhardness data provided the supplementary support for the fingerprinting. The thermal histories of three experimentally heat-treated alloys were well traced and distinguished by the combination of DSC characteristics and electrical conductivity and microhardness results, promoting the DSC application in the quality control and verification of industrial heat treatments. In addition, the microstructures after the various tempers were observed to confirm the evolution of the precipitation reactions revealed in the DSC curves.
\end{abstract}

Keywords: differential scanning calorimetry; heat-treatment tempers; aluminum alloys; precipitation

\section{Introduction}

Heat-treatable cast and wrought aluminum alloys are being widely used to an increasing extent for structural parts in the automotive and aerospace industries. They are usually subjected to a range of thermal histories (heat treatment tempers), depending on their application and the mechanical properties required. These structural parts may occur quality problems during the service related to industrial heat treatments. Therefore, it is necessary to develop an effective approach to determine their thermal histories to enable quick diagnostics and provision of appropriate solutions.

The DSC technique is widely used to investigate solid-state reactions [1], such as precipitation and dissolution processes or other phase transformations in aluminum alloys. During a DSC run with a constant heating rate, materials with different thermal histories will undergo several thermal reactions related to their specific microstructure. Precipitation is accompanied by the release of heat, being an exothermic reaction, while dissolution results in heat absorption as an endothermic reaction. A unique 
DSC curve after each heat treatment may be obtained, each with its individual characteristics, such as the number and size of the exothermic or endothermic peaks as well as the formation temperatures of the peaks. Therefore, the DSC technique provides a possible method for tracing the stages of the microstructural development and fingerprinting the heat-treatment tempers.

Many studies have used DSC to investigate the solid-state reactions in aluminum alloys [2-6], including precipitation and dissolution of precipitates as well as the precipitation kinetics during the heat treatments. For instance, Yassar et al. [2] studied the effects of cold deformation on the kinetics of $\beta^{\prime \prime}-\mathrm{MgSi}$ precipitates in AA6022 alloys and the evolution of precipitation reactions by DSC. Chang et al. [3] reported three clustering reactions that took place in two stages as revealed by low-temperature DSC investigations, the first two of which were linked to the adverse effect of room-temperature preaging, and the third of which exhibited a change in activation energy during room-temperature aging. Ding et al. [7] reported in 6016 aluminum alloy that the peak temperature of $\beta$ " during the DSC analysis varies with the Si and $\mathrm{Cu}$ levels, indicating the different precipitation kinetics. Meanwhile, the precipitation kinetics of 2519A alloy has been systematically investigated by Wu et al. with the DSC technique [5], while Elgallad et al. [4] conducted a DSC study on the effect of quenching rate on the precipitation kinetics of AA2219 DC cast alloy. Heugue et al. [6] used the DSC analysis to develop a method to characterize precipitation kinetics in Al-3.5\%Cu alloy. In a subsequent study [8], they applied this method to investigate the precipitation kinetics of AlSi7Cu3.5Mg0.15 cast alloy. In addition, some calorimetric studies [9-14] focused on the effects of chemical compositions, DSC parameters and process on the precipitation behavior of aluminum alloys. In the study of Weng et al. on Al-Si-Mg alloy [12], it was observed that addition of Ag and Cu decrease the formation temperature of $\beta^{\prime \prime}$ in DSC and accelerate the precipitation rate. Osten et al. [13] studied the dissolution and precipitation behavior during the DSC in a wide range of heat rates in Al-Mg-Si alloy and Liu et al. [14] applied DSC to analyze the static and dynamic precipitation in Al-Mg-Si-Cu alloy after solution treatment and equal channel angular pressing.

However, most of these works focused on the precipitation behavior under certain heat-treatment conditions and used DSC results to explain the microstructure evolution and mechanical properties. In terms of applications of DSC in the determination of the thermal history of a heat-treated alloy, Lloyd et al. [15] studied the precipitation reactions and the DSC responses of the AA6111 automobile alloy during the preaging and paint-baking processes. The characteristics of the reaction peaks on the DSC curves obtained under various heat treatment conditions were analyzed, and the results were used to fingerprint the various precipitation stage. However, very few studies have been realized on the evolution and characteristics of DSC curves of industrial aluminum alloys with different thermal histories, with the aim of establishing their "fingerprints" for various tempers.

In the present work, three commonly used industrial aluminum alloys, namely the high-pressure, die-cast AlSi10Mg0.3Mn alloy, permanent-mold cast Al-Si-Cu 319 alloy, and extruded Al-Mg-Si AA6082 extrusion alloy, have been heat-treated with different tempers. DSC scans of the alloys subjected to different tempers were conducted and analyzed, aiming to systematically study the relationship between heat-treatment tempers and DSC characteristics. Meanwhile, the electrical conductivity and microhardness of the heat-treated samples were measured to provide supplementary support for establishing the DSC fingerprints. In addition, the microstructures of the alloys subjected to various tempers were observed using optical and electron microscopy to confirm the precipitation reactions evidenced in the DSC curves.

\section{Experimental Procedure}

Three industrial aluminum alloys were investigated in the present work. The AlSi10Mg0.3Mn alloy was supplied in the form of a $220 \mathrm{~mm} \times 65 \mathrm{~mm} \times 3 \mathrm{~mm}$ plate fabricated by the high-pressure vacuum die-casting (HPVDC) by Arvida Research and Development Centre, Rio Tinto Aluminum (Saguenay, QC, Canada). The Al-Si-Cu 319 alloy was supplied in the form of a $\phi 20 \mathrm{~mm} \times 35 \mathrm{~mm}$ cylindrical bar fabricated by permanent mold (PM) casting, while Al-Mg-Si AA6082 alloy was supplied 
in the form of a 3-mm-thick plate after extrusion by Arvida Research and Development Centre, Rio Tinto Aluminum (Saguenay, QC, Canada). The chemical compositions of the three aluminum alloys are listed in Table 1. Various heat treatments were applied to the studied alloys, including the " $\mathrm{F}^{\prime}$, "SHT", "T4", "T5", "T6", and "T7", which are described in detail in Table 2.

Table 1. Chemical compositions of the studied alloys (wt.\%).

\begin{tabular}{cccccccccccc}
\hline Alloy & Si & $\mathbf{C u}$ & $\mathbf{M g}$ & $\mathbf{M n}$ & $\mathbf{F e}$ & $\mathbf{T i}$ & $\mathbf{S r}$ & $\mathbf{V}$ & $\mathbf{Z r}$ & $\mathbf{C r}$ & Al \\
\hline AlSi10Mg0.3Mn & 10.63 & - & 0.315 & 0.53 & 0.17 & 0.05 & 0.014 & 0.012 & - & - & Bal. \\
319 & 7 & 3.5 & 0.15 & 0.15 & 0.12 & 0.1 & 0.015 & 0.1 & 0.12 & - & Bal. \\
6082 & 0.9 & - & 0.7 & 0.5 & 0.2 & - & - & - & - & 0.1 & Bal. \\
\hline
\end{tabular}

Table 2. Various heat treatments applied to the experimental alloys.

\begin{tabular}{cccc}
\hline Temper & AlSi10Mg0.3Mn & 319 & $\mathbf{6 0 8 2}$ \\
\hline $\mathrm{F}^{1}$ & HPVDC plate & PM cast bar & Extruded strip \\
$\mathrm{SHT}^{2}$ & $500{ }^{\circ} \mathrm{C} / 1 \mathrm{~h}$ & $505^{\circ} \mathrm{C} / 4 \mathrm{~h}$ & $540{ }^{\circ} \mathrm{C} / 0.5 \mathrm{~h}$ \\
$\mathrm{~T} 4$ & $\mathrm{~N} / \mathrm{A}$ & $\mathrm{N} / \mathrm{A}$ & $\mathrm{SHT}+\mathrm{WQ}{ }^{3}+$ natural aging for $1,7 \& 28$ days \\
$\mathrm{T} 5$ & $\mathrm{~F}+185^{\circ} \mathrm{C} / 4 \mathrm{~h}$ & $\mathrm{~F}+180^{\circ} \mathrm{C} / 5 \mathrm{~h}$ & $\mathrm{~F}+175^{\circ} \mathrm{C} / 8 \mathrm{~h}$ \\
$\mathrm{~T} 6$ & $\mathrm{SHT}+\mathrm{WQ}+185^{\circ} \mathrm{C} / 4 \mathrm{~h}$ & $\mathrm{SHT}+\mathrm{WQ}+180^{\circ} \mathrm{C} / 5 \mathrm{~h}$ & $\mathrm{SHT}+\mathrm{WQ}+175^{\circ} \mathrm{C} / 8 \mathrm{~h}$ \\
$\mathrm{~T} 7$ & $\mathrm{SHT}+\mathrm{WQ}+220^{\circ} \mathrm{C} / 4 \mathrm{~h}$ & $\mathrm{SHT}+\mathrm{WQ}+200^{\circ} \mathrm{C} / 5 \mathrm{~h}$ & $\mathrm{~N} / \mathrm{A}$ \\
\hline
\end{tabular}

Note: ${ }^{1}$ " $\mathrm{F}$ " indicates the as-received condition; " ${ }^{2} \mathrm{SH}$ " is the solution heat treatment condition; " ${ }^{3} \mathrm{~W}$ " means the water quench after SHT.

After heat treatments, the DSC experiments were performed using a computerized differential scanning calorimeter (Perkin-Elmer DSC 8000, Waltham, MA, USA). The mass of each sample was approximately 20-30 mg. A protective atmosphere of pure argon gas with a gas flow of $60 \mathrm{~mL} / \mathrm{min}$ was used. The sample was analyzed over the temperature range of 50 to $550{ }^{\circ} \mathrm{C}$, at a constant heating rate of $10^{\circ} \mathrm{C} / \mathrm{min}$. Three samples were analyzed for each temper. To improve the DSC resolution, a piece of high-purity aluminum (99.999\%) with a weight similar to that of the test sample was placed in the reference crucible for each scan. To make the DSC results comparable between tempers, the correction and normalization of the DSC curves under a common procedure is essential, and thus the original DSC curves in the present work were corrected and normalized using a three-step procedure [6], which is shown in Figure 1 with an example in the F tempers of AlSi10Mg0.3Mn alloy. The first step was the subtraction of the instrumental baseline (Figure 1a), which was measured using high-purity aluminum with the same weight in both the sample and reference crucibles. The second step was the subtraction of the heat-effect baseline (Figure 1b), which was done using a polynomial or a Gaussian function [16]. Finally, the curve was normalized by dividing the mass of the test sample (Figure 1c). After correction and normalization, the characteristics of the DSC curve were analyzed, including the number and sizes of peaks as well as their onset/peak/end temperatures.

The microstructures, including the morphology and distribution of secondary phases, were observed by optical microscopy. The details of precipitation were examined by transmission electron microscopy (TEM; JEOL JEM-2100, Akishima, Tokyo, Japan ). TEM samples were prepared in an electrochemical twin-jet machine at $-20^{\circ} \mathrm{C}$ and $20 \mathrm{~V}$ using a solution of $25 \%$ nitric acid in methanol. The number density of precipitations $(D)$ was calculated with the following equation $[17,18]$ :

$$
D=\frac{3 N_{\|}}{A(t+l)}
$$

where $N_{\|}$is the number of precipitates in the imaged area $A, t$ is the area thickness measured according to reported procedures $[19,20]$, and $\langle l\rangle$ is the average needle length. The factor of 3 accounts for the three equivalent directions of $\langle l 00\rangle_{\mathrm{Al}}$.

In addition, Vickers microhardness tests were conducted using a NG-1000CCD microhardness testing system (Vancouver, BC, Canada) with a load of 10 or $25 \mathrm{gf}$ depending on the grain structure 
(herein represented as HV0.010 and HV0.025, respectively) and a dwell time of $15 \mathrm{~s}$, for at least 10 measurements per condition. Electrical conductivity was also measured on polished samples using a Sigmascope SMP10 (Windsor, CT, USA) instrument, with measurements performed in triplicate.
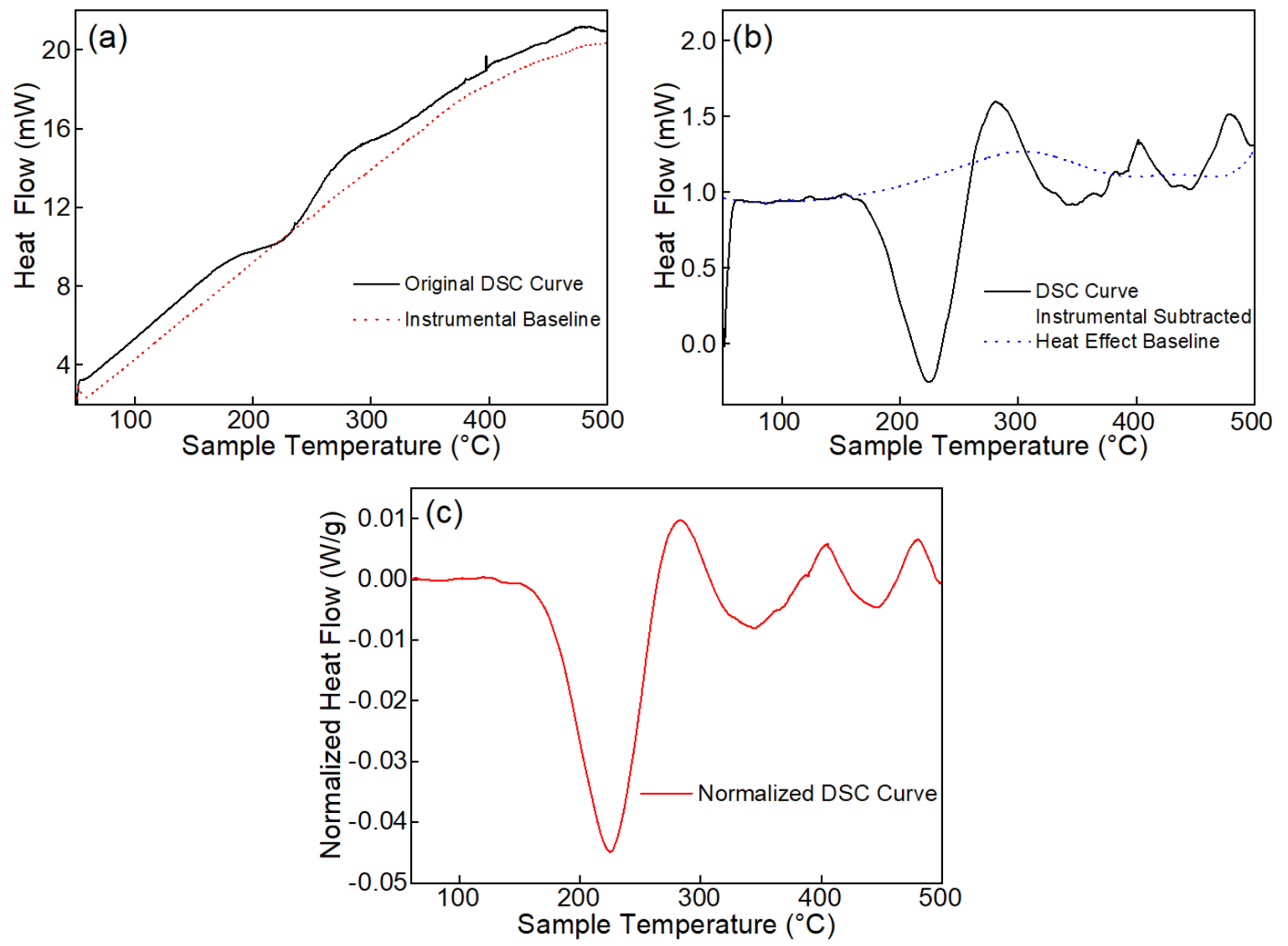

Figure 1. Correction process of the DSC curves: (a) subtraction of instrumental baseline; (b) subtraction of heat-effect baseline; and (c) normalization according to the mass of the sample.

\section{Results and Discussion}

\subsection{AlSi10Mg0.3Mn HPVDC Alloy}

Figure 2a shows the DSC heating curves of the AlSi10Mg0.3Mn alloy subjected to the F (as-cast) and SHT treatments, while Figure $2 \mathrm{~b}$ shows those for the T5, T6, and T7 tempers. As shown in Figure 2a, three obvious exothermic peaks, $a, b$, and $c$, located at temperatures of approximately 240, 330 , and $430{ }^{\circ} \mathrm{C}$, respectively, are evident for both $\mathrm{F}$ and SHT, and are related to the precipitation of $\beta^{\prime \prime}$, $\beta^{\prime}$, and $\beta$, respectively $[3,21]$. On the other hand, as shown in Figure $2 b$, the curves for both the T5 and T6 tempers show only two exothermic peaks, $b^{\prime}$ and $c^{\prime}$, located at temperatures of approximately 340 and $420^{\circ} \mathrm{C}$, respectively, which are related to the precipitation of $\beta^{\prime}$ and $\beta$, respectively, while only one major exothermic peak, $c^{\prime \prime}$, located at $370^{\circ} \mathrm{C}$, was detected for the T7 sample, which can be related to the precipitation of $\beta$ [21]. In addition, three endothermic peaks (I, II, and III) can be observed in Figure 2, and are related to the dissolution of the specific phases. According to the literature $[3,21]$, Peak I represents the dissolution of $\beta^{\prime \prime}$, while Peak II refers to the dissolution of $\beta^{\prime}$, and Peak III for the dissolution of the $\beta$ phase. The characteristics of the DSC curves corresponding to the various tempers are summarized in Table 3.

The identifications for all tempers are marked in bold in Table 3, principally on the exothermic peaks, which can be recognized as the fingerprint for each temper of the AlSi10Mg0.3Mn HPVDC alloy. Based on the observations shown in Figure 2 and the summary in Table 3, the most significant difference between tempers is exhibited in the number and size of exothermic peaks. There were 
3 exothermic peaks presented after both F and SHT treatments, while there were only 2 for each of T5 and T6 but only 1 for T7. Differences in the sizes of the peaks (peak areas) can be helpful in further distinguishing the temper. For instance, the areas of Peak $a$ and Peak $b$ ( $\beta^{\prime \prime}$ and $\beta^{\prime}$ precipitates) in F are much larger than those in SHT (Figure 2a), while the area of Peak $c$ ( $\beta$ precipitates) in T7 is significantly larger than that in both T5 and T6. As calculated from the DSC curves (Figure 2), the areas of Peak $a$ in F and SHT are 14.5 and $4.0 \mathrm{~J} / \mathrm{g}$, respectively. Similarly, the area of Peak $c$ in T7 is $4.6 \mathrm{~J} / \mathrm{g}$, but only 1.0 and $0.7 \mathrm{~J} / \mathrm{g}$ in $\mathrm{T} 5$ and T6 (Table 3), respectively.
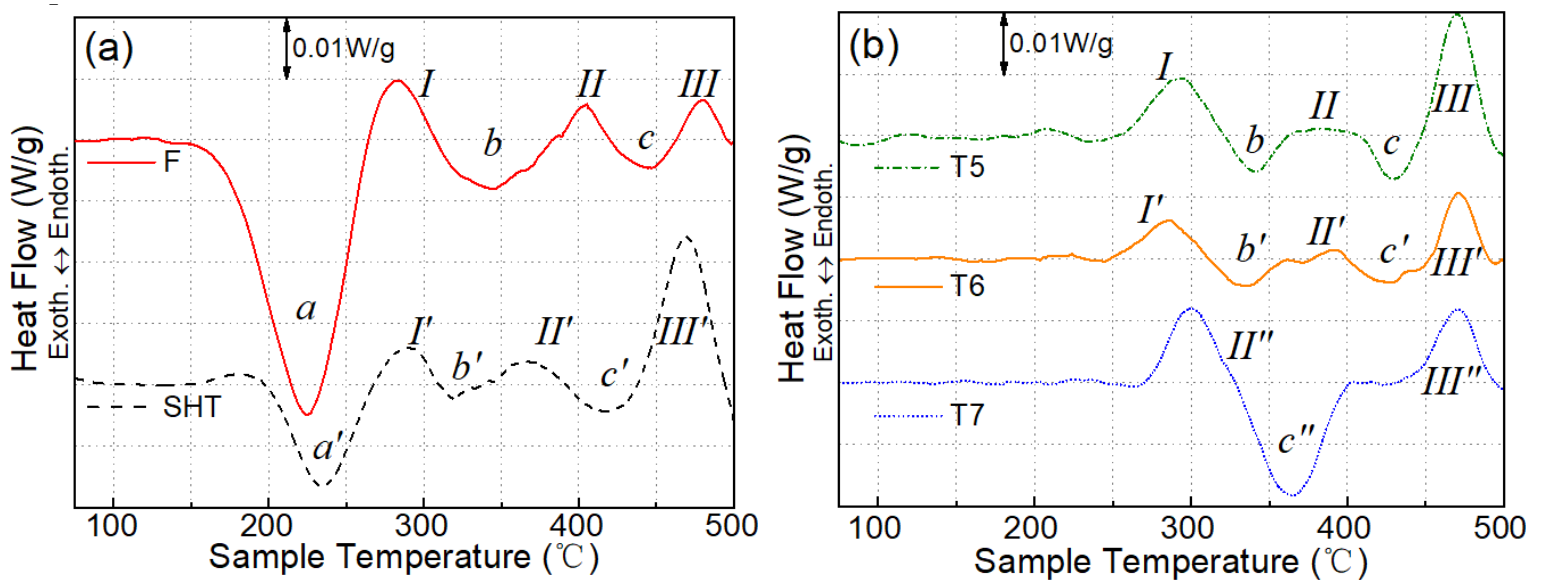

Figure 2. DSC heating curves of AlSi10Mg0.3Mn alloy subject different treatments: (a) F and SHT; (b) T5, T6, and T7.

Table 3. Summary of DSC characteristics of the various tempers of the AlSi10Mg0.3Mn alloy.

\begin{tabular}{|c|c|c|c|c|c|c|}
\hline Temper & $\begin{array}{l}\text { Exo. Peak } a \\
\text { Series (Peak } \\
\text { Temp./Area) }\end{array}$ & $\begin{array}{l}\text { Endo. Peak I } \\
\text { Series }\end{array}$ & $\begin{array}{l}\text { Exo. Peak } b \\
\text { Series }\end{array}$ & $\begin{array}{l}\text { Endo. Peak II } \\
\text { Series }\end{array}$ & $\begin{array}{c}\text { Exo. Peak } c \\
\text { series (Peak } \\
\text { Temp./Area) }\end{array}$ & $\begin{array}{c}\text { Endo. Peak } \\
\text { III Series }\end{array}$ \\
\hline $\mathrm{F}$ & $\beta^{\prime \prime}, 230^{\circ} \mathrm{C} / 14.5$ & & $\beta^{\prime}, 340^{\circ} \mathrm{C} / 2.3$ & & $\beta, 440^{\circ} \mathrm{C} / 0.7$ & \\
\hline SHT & $\beta^{\prime \prime}, 240{ }^{\circ} \mathrm{C} / 4.0$ & & $\beta^{\prime}, 320^{\circ} \mathrm{C} / 0.2$ & & $\beta, 420^{\circ} \mathrm{C} / 0.8$ & \\
\hline $\mathrm{T} 5$ & - & $\beta^{\prime \prime}$ dissolution & $\beta^{\prime}, 340{ }^{\circ} \mathrm{C} / 0.8$ & $\beta^{\prime}$ dissolution & $\beta, 430{ }^{\circ} \mathrm{C} / 1.0$ & $\beta$ dissolution \\
\hline T6 & - & & $\beta^{\prime}, 340{ }^{\circ} \mathrm{C} / 0.7$ & & $\beta, 420^{\circ} \mathrm{C} / 0.7$ & \\
\hline $\mathrm{T} 7$ & - & - & - & & $\beta, 370^{\circ} \mathrm{C} / 4.6$ & \\
\hline
\end{tabular}

In addition to the DSC runs, the microstructures of the AlSi10Mg0.3Mn alloy after the various tempers were observed (Figure 3). It was found that in the samples not subjected to the solution treatment (F in Figure $3 \mathrm{a}$ and T5 in Figure 3c), the eutectic Si was very fine and formed a network around aluminum dendrites, owing to the high cooling rate of the HPVDC process. However, after solution treatment (including SHT (Figure 3b), T6 (Figure 3d), and T7 (Figure 3e), the eutectic Si transformed to separated particles and became coarser. Therefore, the evolution of microstructure, especially the changes of eutectic Si particles, can be used to clarify between the tempers with and without the solution treatment.

Although the tempers can essentially be identified according to the number and size of exothermic peaks in the DSC curves, the measurements of electrical conductivity (EC) and microhardness can provide further confirmation for certain temper. The results of the EC and microhardness of sample after different treatments are shown in Figure 4. For example, it was found that the EC of the sample at F temper was remarkably lower than that of the SHT sample. For the F temper, a large number of solute atoms were retained in the aluminum matrix due to the high cooling rate and high-pressure temperature of the HPVDC process, and their concentrations might be higher than the solubility limit at solidus temperature [1,22]. Together with the fine network of eutectic Si (Figure 3a), this resulted in the F condition having the lowest EC among all the tempers. To avoid the possible blister defect in HPVDC products, the solution temperature was set to a relatively low temperature $\left(500^{\circ} \mathrm{C}\right)$. Therefore, the solid solution level after the SHT treatment was still relatively lower than that for the F condition, 
resulting in the higher EC of the former. In addition, the network of eutectic Si was fragmented into separate particles and became coarser after the SHT treatment (Figure 3b), which also contributed to a certain extent to its higher EC. On the other hand, because of the similarity between the DSC curves of T5 and T6 tempers (each exhibiting two exothermic peaks at similar temperatures (Figure 2b), the difference was less obvious between these two tempers. For a further confirmation, the results of Figure 4 indicate that the EC of T5 was remarkably lower than that of T6, and the microhardness of T5 was also lower than that of T6. In summary, with the supplementary support of EC and microhardness data, the various tempers of the AlSi10Mg0.3Mn HPVDC alloy can be well identified and distinguished.
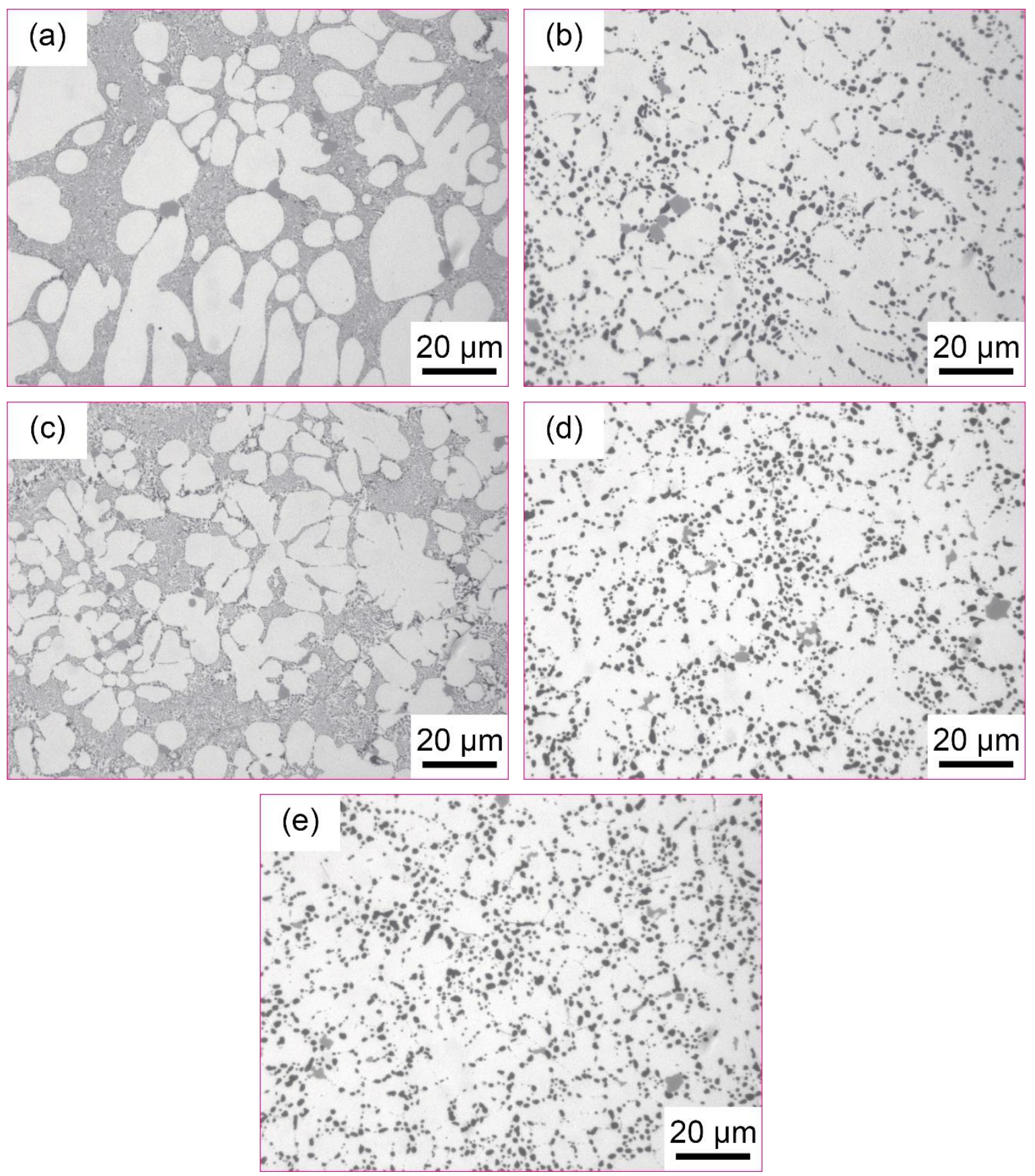

Figure 3. Microstructures of the AlSi10Mg0.3Mn alloy subjected different treatments: (a) F; (b) SHT; (c) T5; (d) T6; and (e) T7. 


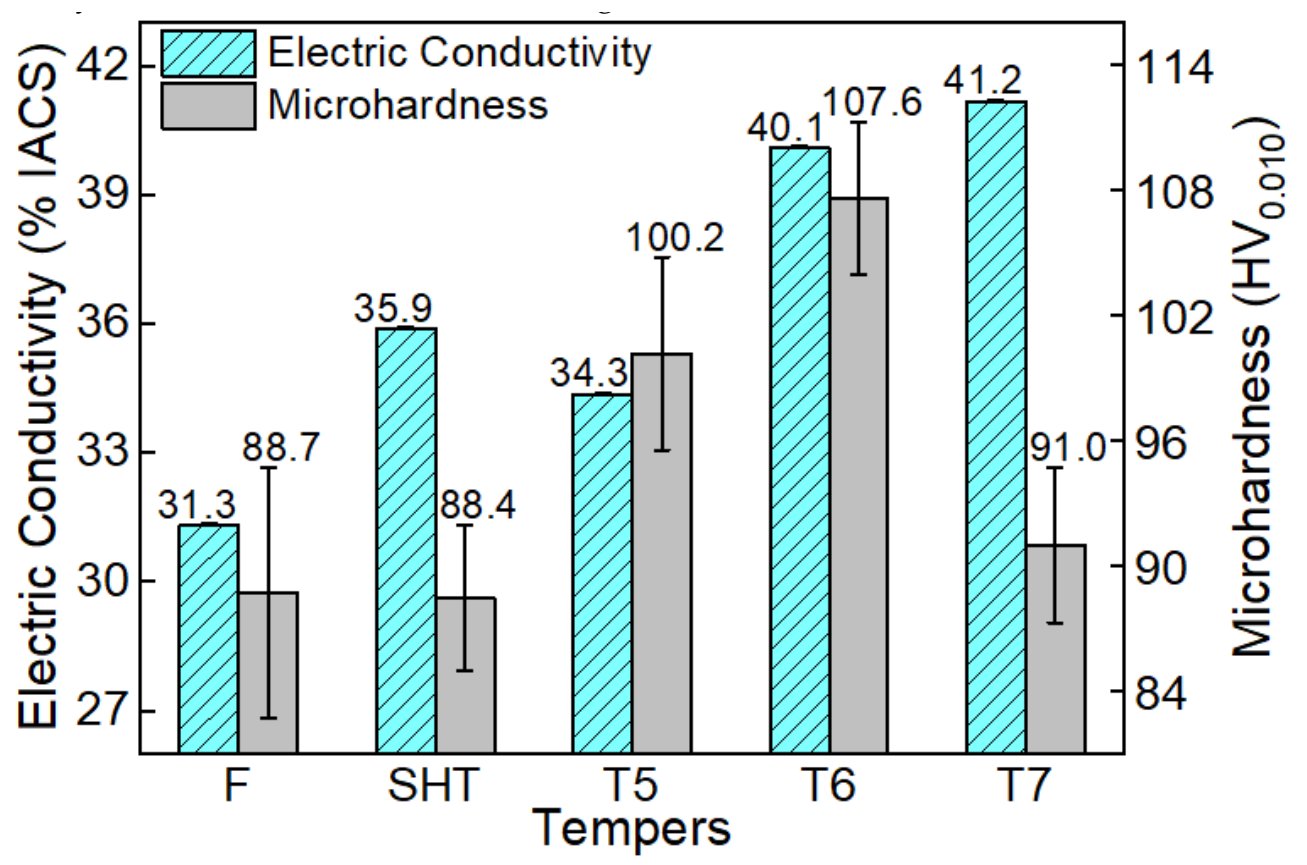

Figure 4. Electrical conductivity and microhardness after different treatments of AlSi10Mg0.3Mn alloy.

To find the root causes of the different numbers of reactions (peaks) in the DSC curves, precipitation after the aging process (T5, T6, and T7) was investigated using TEM. As shown in Figure 5, the precipitates were found to vary greatly with the temper. For Al-Si-Mg foundry alloys (AlSi10Mg0.3Mn here and Al-Mg-Si AA6082 extrusion alloy in Section 3.3), the precipitation sequence of the strengthening phases is well known, and occurs as follows [23-25]:

Supersaturated solid solution $\rightarrow \mathrm{Mg} /$ Si clusters $\rightarrow \mathrm{GP}(\mathrm{I})$ zones $\rightarrow \beta^{\prime \prime} \rightarrow \beta^{\prime} \rightarrow \beta$

After the T5 temper (Figure 5a), there was a mixture of the needle-like precipitates $\left(\beta^{\prime \prime}\right)$ and rod-like/granular precipitates, which are assumed to be intermediate precipitates containing $\mathrm{Mg}$ and $\mathrm{Si}$ in high-pressure die-casting Al-Si-Mg alloy [22]. The microstructure after T6 mainly contain needle-like and fine $\beta^{\prime \prime}$ precipitates (Figure $5 \mathrm{~b}$ ), while needle-like and large $\beta^{\prime}$ precipitates were predominant after the T7 temper (Figure 5c). The different precipitates shown in Figure 5 also explain the appearance of various peaks in the DSC curves (Figure 2). Under the conditions of the F and SHT treatments, due to the supersaturated solid solution matrix, the first precipitation event that occurred during the DSC heating was of $\beta^{\prime \prime}$ (Peak $a$ ), followed by precipitations of $\beta^{\prime}$ (Peak $b$ ) and $\beta$ (Peak $c$ ), which resulted in the three exothermic peaks observed. However, the $\beta^{\prime \prime}$ or intermediate precipitates already formed in T5 and T6 samples, and thus the first endothermic peak corresponded to the dissolution of $\beta^{\prime \prime}$ (Peak $\left.I\right)$, followed by two exothermic peaks corresponding to the precipitations of $\beta^{\prime}$ and then $\beta$. In the T7 temper, since $\beta^{\prime}$ has already formed in the matrix (Figure $5 \mathrm{c}$ ), the first reaction was the dissolution of $\beta^{\prime}$ (endothermic Peak II), which appeared after the sole exothermic peak corresponding to the precipitation of $\beta$. Due to the pre-existing $\beta^{\prime}$ in the T7 temper, the peak area of $\beta$ (Peak $c$ ) was much larger and the peak appeared earlier than those in T5 and T6 (Figure 2b). In addition, the size and number density of precipitates in $\mathrm{T} 6$ and $\mathrm{T} 7$ also varied greatly. As shown in Figure $5 \mathrm{~d}$, the number density and average length of $\beta^{\prime \prime}$ in T6 were $13696 \mu \mathrm{m}^{-3}$ and $79.6 \mu \mathrm{m}$, respectively. However, the precipitates were more scarce and larger after T7 temper, in which the number density and average length of $\beta^{\prime}$ were $7556 \mu \mathrm{m}^{-3}$ and $212.7 \mu \mathrm{m}$, owing to the over-aging process [7], further explaining the much lower microhardness after T7 than that after T6 (Figure 3). 

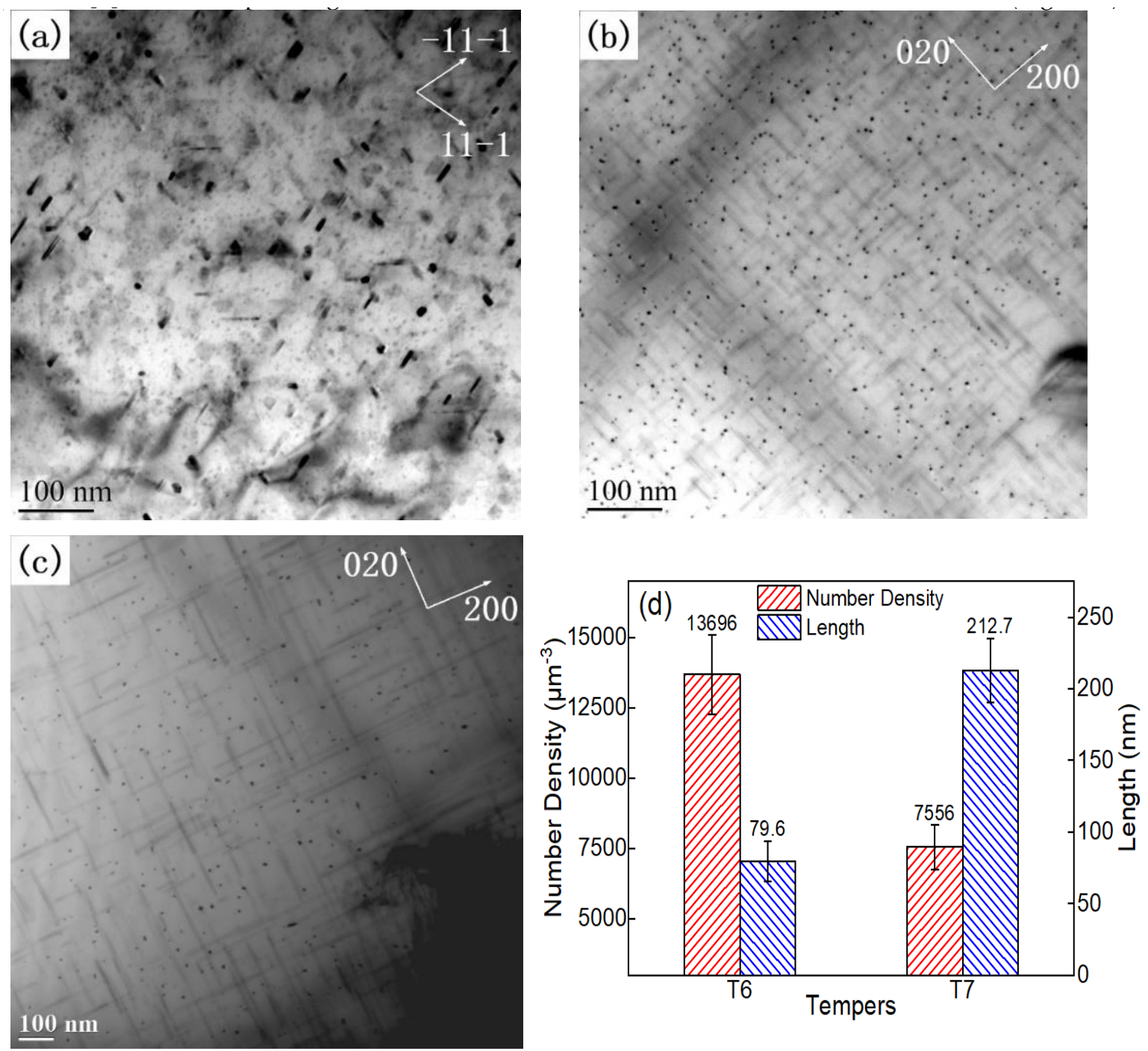

Figure 5. Precipitation after: (a) T5, (b) T6, and (c) T7, and their characteristics after T6 and T7 (d).

\subsection{Al-Si-Cu-Mg 319 PM Alloy}

The Al-Si-Cu-Mg 319 alloy is one of most used aluminum foundry alloys in the automobile industry. Figure 6 illustrates the DSC heating curves of Al-Si-Cu-Mg 319 PM alloys subjected to various tempers. For both F (as-cast) and SHT (Figure 6a), there were three exothermic peaks $(b, c$, and $d$ ) located at temperatures of approximately 160,240 , and $390{ }^{\circ} \mathrm{C}$, respectively, which are related to the precipitations of GP zones (Peak $b), \theta^{\prime}(\operatorname{Peak} c)$, and $\theta$ (Peak $d$ ) [26-30]. In addition, two more exothermic peaks were observed in the DSC curve after SHT treatment: one located at approximately $105^{\circ} \mathrm{C}$, which can be recognized as the formation of clusters [31], and the other overlapping with Peak $c^{\prime}$ at approximately $260^{\circ} \mathrm{C}$ (marked as Peak $c^{\prime \prime}$ ), which is considered as the precipitation of $Q^{\prime}[26,28,29,31]$. The DSC curves for the tempers involving aging (T5, T6, and T7) are shown in Figure 6b. For the $\mathrm{T} 5$ and $\mathrm{T} 6$ tempers, two exothermic peaks $(c$ and $d$ ) are observed on the curves, which are located at nearly the same temperatures as those in Figure 6a, and are related to the precipitation of $\theta^{\prime}$ and $\theta$, respectively. On the other hand, after the T7 temper, only one exothermic peak $d$, corresponding to the precipitation of $\theta$, was detected.

As seen in Figure 6, three endothermic peaks are observed in addition to the exothermic peaks, which are dependent on the temper. As shown in Figure 6a, two endothermic peaks (Peaks II and III) can be observed at the temperatures of $\sim 300$ and $\sim 470{ }^{\circ} \mathrm{C}$, and are recognized as corresponding to the dissolutions of $\theta^{\prime}$ and $\theta$ precipitates, respectively [30]. Under the aging conditions (Figure 6b), 
one more endothermic peak (Peak $I$ ) at the temperature of $\sim 260{ }^{\circ} \mathrm{C}$ was observed, which is considered to correspond to the dissolution of $Q^{\prime}$ precipitates [27]. Details of the various peaks detected in the DSC curves of the various tempers is summarized in Table 4.
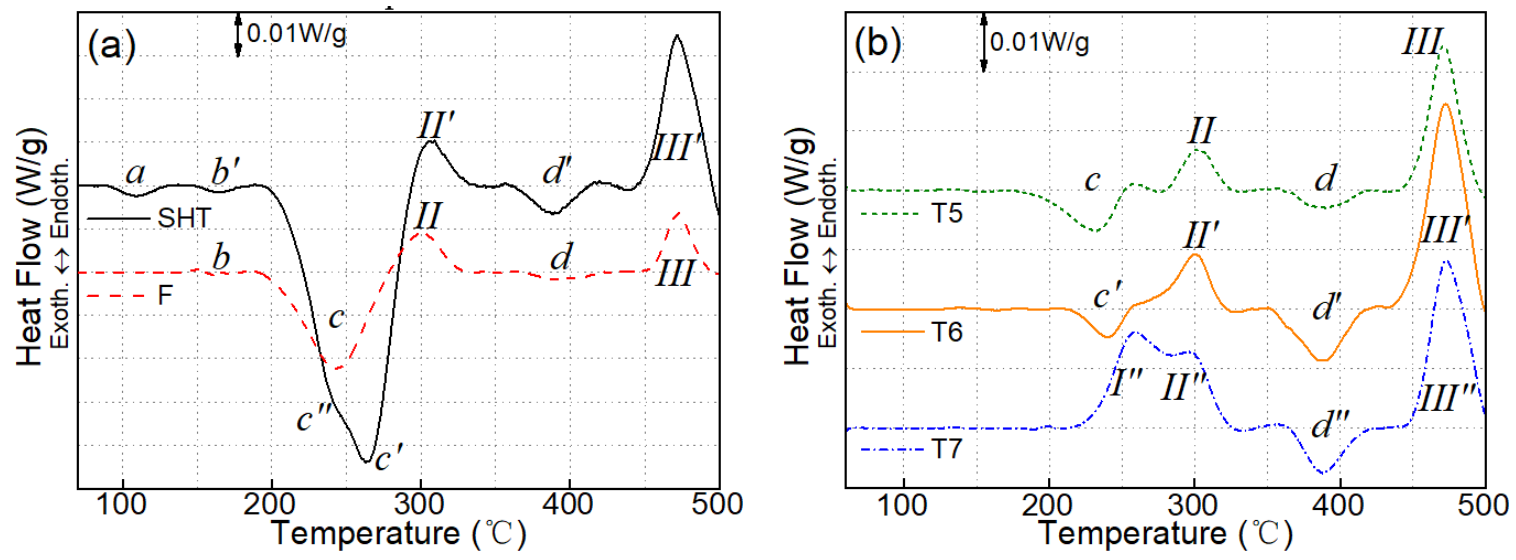

Figure 6. DSC heating curves of the Al-Si-Cu-Mg 319 alloy subjected to different treatments: (a) F and SHT; (b) T5, T6, and T7.

Table 4. Summary of DSC characterization of the tempers of the Al-Si-Cu-Mg 319 alloy.

\begin{tabular}{|c|c|c|c|c|c|c|c|}
\hline Temper & $\begin{array}{l}\text { Exo. Peak } a \\
\text { Series }\end{array}$ & $\begin{array}{c}\text { Exo. Peak } b \\
\text { Series }\end{array}$ & $\begin{array}{l}\text { Exo. Peak } c \\
\text { Series (Peak } \\
\text { Temp./Area) }\end{array}$ & $\begin{array}{l}\text { Exo. Peak } c / \\
\text { Endo. Peak I }\end{array}$ & $\begin{array}{c}\text { Endo. Peak II } \\
\text { Series }\end{array}$ & $\begin{array}{l}\text { Exo. Peak } d \\
\text { Series (Peak } \\
\text { Temp./Area) }\end{array}$ & $\begin{array}{l}\text { Endo. } \\
\text { Peak III } \\
\text { Series }\end{array}$ \\
\hline $\mathrm{F}$ & $\times$ & & $\theta^{\prime}, 240^{\circ} \mathrm{C} / 5.9$ & $\times$ & \multirow{4}{*}{$\theta^{\prime}$ dissolute } & $\theta, 400{ }^{\circ} \mathrm{C} / 0.4$ & \multirow{4}{*}{$\theta$ dissolute } \\
\hline SHT & Clusters, $110^{\circ} \mathrm{C}$ & GP zones, $160^{\circ} \mathrm{C}$ & $\theta^{\prime}, 260^{\circ} \mathrm{C} / 19.6$ & $Q^{\prime}, 240^{\circ} \mathrm{C}$ & & $\theta, 390{ }^{\circ} \mathrm{C} / 1.1$ & \\
\hline $\mathrm{T} 5$ & - & - & $\theta^{\prime}, 240^{\circ} \mathrm{C} / 1.4$ & $\widetilde{Q^{\prime}}$ dissolute & & $\theta, 390{ }^{\circ} \mathrm{C} / 0.6$ & \\
\hline T6 & - & - & $\theta^{\prime}, 240^{\circ} \mathrm{C} / 0.6$ & $\widetilde{Q}^{\prime}$ dissolute & & $\theta, 390^{\circ} \mathrm{C} / 1.8$ & \\
\hline
\end{tabular}

As revealed by the data shown in Figure 6 and Table 4, the different tempers of the Al-Si-Cu-Mg 319 alloy can be principally identified by their specific DSC characteristics, particularly in the number and size of exothermic peaks (marked in bold in Table 4). As shown in Figure 6a, the differences between the DSC curves of the samples after F and SHT treatments are apparent; three exothermic peaks are detectable for the F temper, while five exothermic peaks are detectable for the SHT treatment. In addition, the area of Peak $c$ of the SHT treatment $(19.6 \mathrm{~J} / \mathrm{g})$ was much larger than that of the F temper $(5.9 \mathrm{~J} / \mathrm{g})$, and the area of Peak $d$ of the SHT condition $(1.1 \mathrm{~J} / \mathrm{g})$ was also greater than that of the F condition $(0.4 \mathrm{~J} / \mathrm{g})$. For the treatment conditions involving aging (Figure $6 \mathrm{~b}$ ), both T5 and T6 exhibited two exothermic peaks, while only one exothermic peak was detected for T7. In the cases of T5 and T6, the sizes of the peaks differed significantly (Table 4). For the T5 sample, the first peak (Peak $c$, at $\sim 240{ }^{\circ} \mathrm{C}$ ) was large and was followed by a second smaller peak (Peak $d$, at $\sim 390^{\circ} \mathrm{C}$ ). On the contrary, the T6 has the first smaller peak (Peak $c$, at $\sim 240{ }^{\circ} \mathrm{C}$ ) and the second larger peak (Peak $d$, at $\sim 390{ }^{\circ} \mathrm{C}$ ) compared with T5. Therefore, the different tempers of the Al-Si-Cu-Mg 319 alloy can be distinguished well by their DSC fingerprints.

In addition to the DSC analysis, the microstructures of Al-Si-Cu-Mg 319 alloy subjected to the F (as-cast) and SHT treatments of the were observed (Figure 7), and the EC and microhardness after the different treatments were also measured (Figure 8). As shown in Figure 7a, in the F (as-cast) condition, not only a network of fine eutectic $\mathrm{Si}$ around aluminum dendrites but also a reasonable amount of $\mathrm{Al}_{2} \mathrm{Cu}$ intermetallic was present in the matrix due to the relatively low cooling rate applied in permanent mold casting. However, after SHT treatment (Figure $7 \mathrm{~b}$ ), $\mathrm{Al}_{2} \mathrm{Cu}$ intermetallic was fully dissolved in the matrix and eutectic $S i$ had been fragmented into separated particles, resulting in a much higher supersaturated solid solution level compared to that of the F condition. Therefore, the microhardness was significantly higher while the EC was lower after SHT treatment in comparison to those of the F condition (Figure 8), providing further evidence to assist in the differentiation between the $F$ and 
SHT treatments. After T5 and T6, the results in Figure 8 show that the EC and microhardness after T6 are considerably higher than those after T5. Thus, with the supplementary EC and microhardness data, the various tempers of the Al-Si-Cu-Mg 319 alloy can be clearly identified.

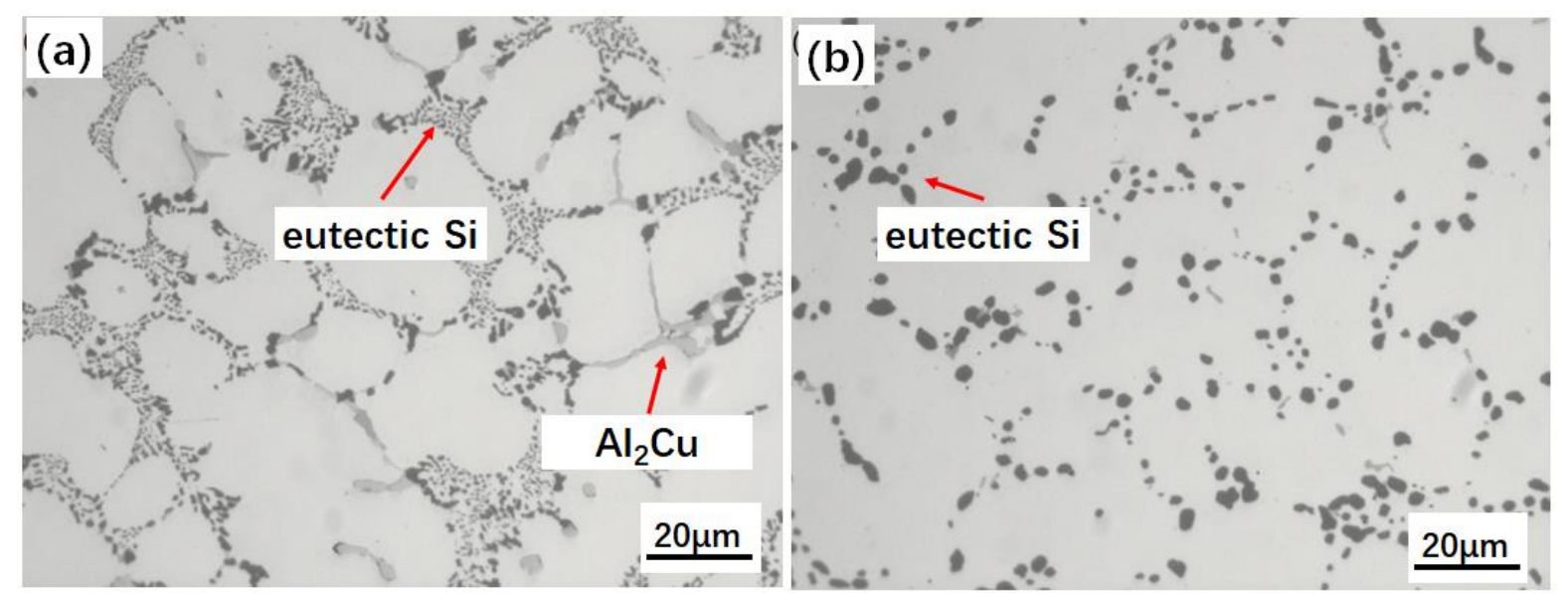

Figure 7. Microstructures of the Al-Si-Cu-Mg 319 alloy subjected different treatments: (a) F and (b) SHT.

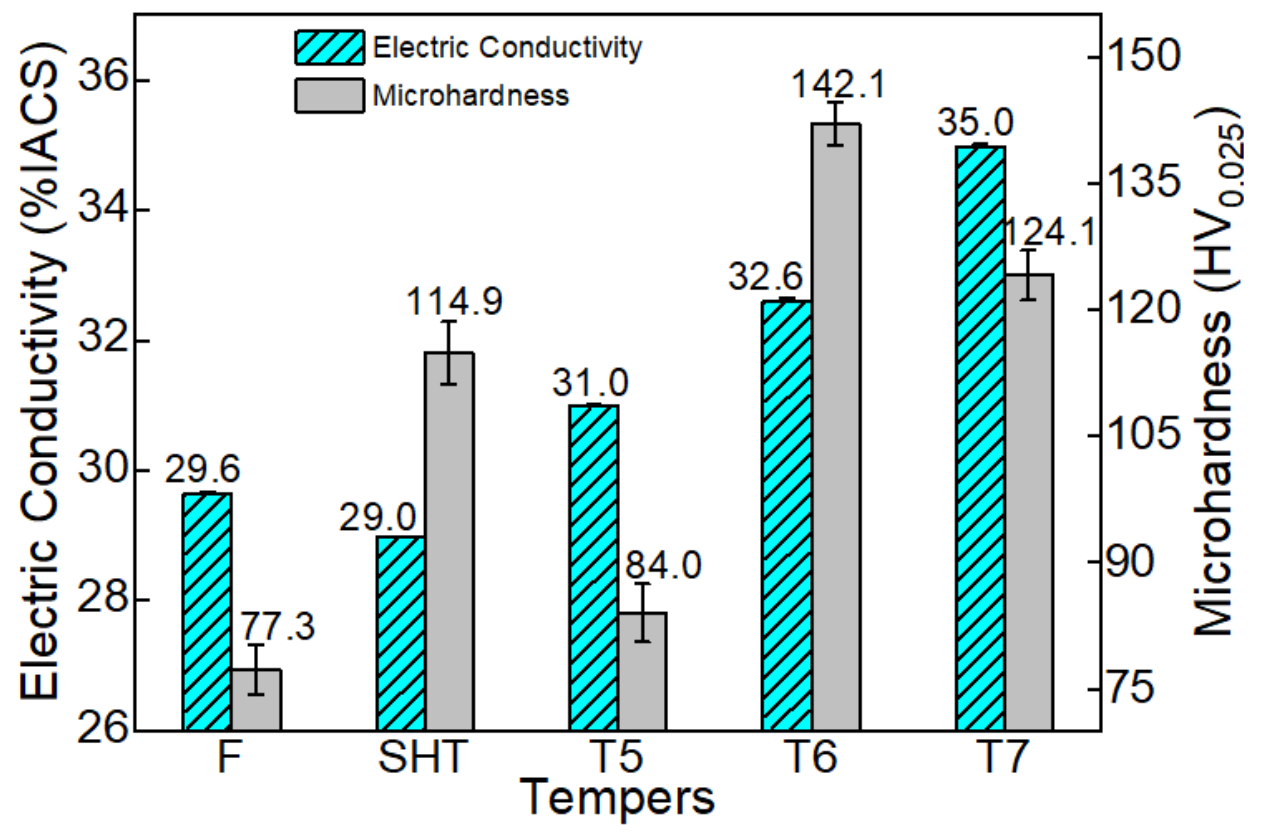

Figure 8. Electrical conductivity and microhardness of the Al-Si-Cu-Mg 319 alloy after different treatments.

To further confirm the precipitation reactions revealed in the DSC curves, the precipitation behavior under different aging conditions (T5, T6, and T7) was investigated using TEM and results are shown in Figure 9.

In the heat-treatable Al-Si-Mg-Cu alloys, the principal precipitation sequence of the strengthening phases is presented as follows [32,33]:

Supersaturated solid solution $\rightarrow$ atomic clusters $\rightarrow \mathrm{GP}(\mathrm{I})$ zones $\rightarrow \theta^{\prime \prime} \rightarrow \theta^{\prime} \rightarrow \theta$ 

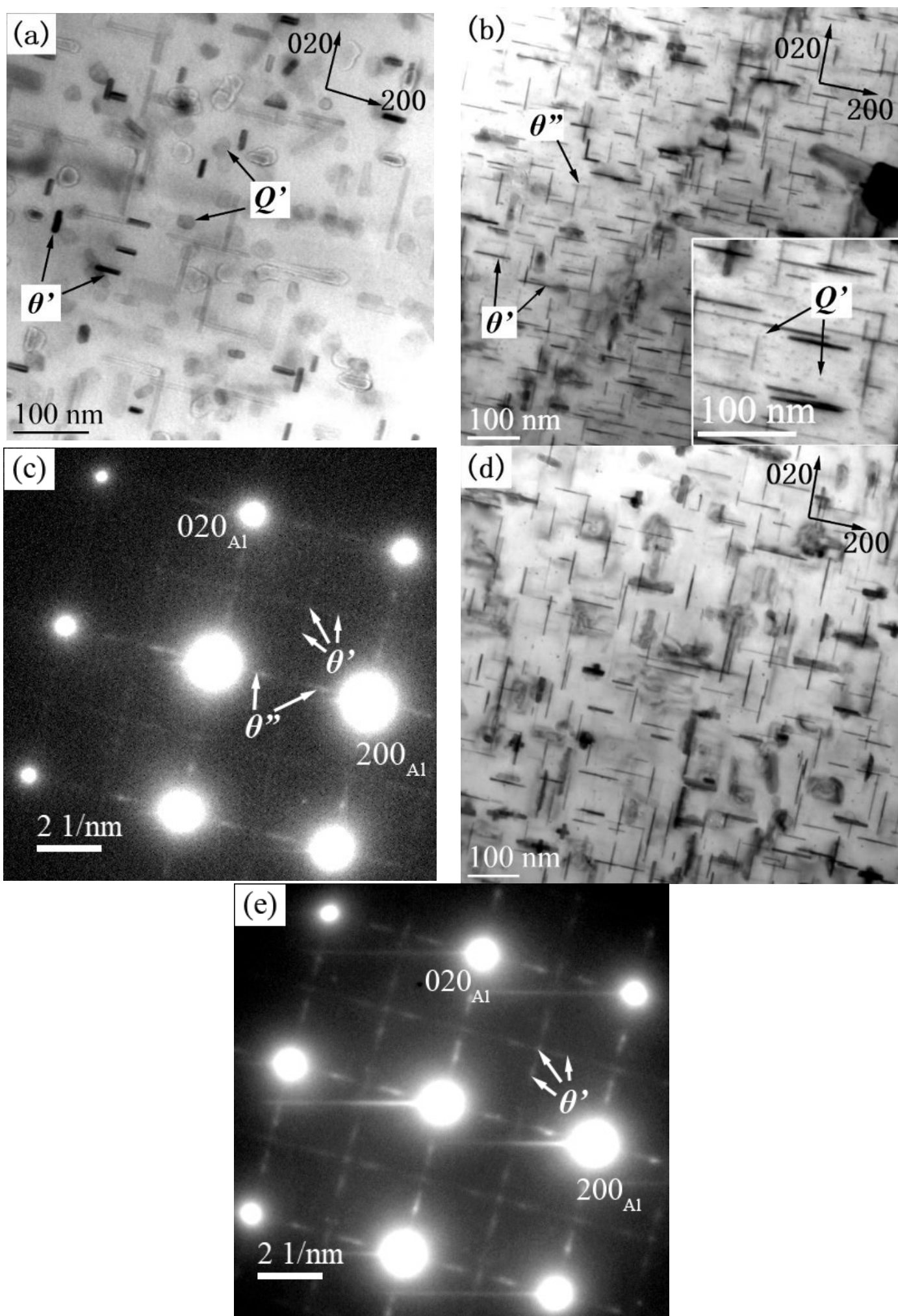

Figure 9. TEM bright-field images of the Al-Si-Cu-Mg 319 alloy after (a) T5, (b) T6, and (d) T7, and the corresponding SADPs for (c) T6 and (e) T7.

In the multicomponent industrial aluminum foundry alloys, such as the $\mathrm{Al}-\mathrm{Si}-\mathrm{Cu}-\mathrm{Mg} 319$ alloy studied herein, the precipitation sequence may become more complicated owing to the formation of the $Q$ phase (a quaternary Al-Si-Cu-Mg phase) and its precursors. As shown in Figure $9 \mathrm{a}$, after $\mathrm{T} 5$, two precipitates are coincidently existed in the aged microstructure, namely a major $\theta^{\prime}$ phase 
with a rectangular shape, distributed along the (200) and (020) orientations, and a minor $Q^{\prime}$ phase which appeared as fine round particles [34,35]. After T6 (Figure 9b), the microstructure of sample consisted of a minor $\theta^{\prime \prime}$ phase and a major $\theta^{\prime}$ phase with a lath-like morphology [27,29], which can be identified by the mixture of weak strikes and strong points in the selected area diffraction pattern (SADP) shown in Figure 9c [36]. Therefore, both $\theta^{\prime \prime}$ and $\theta^{\prime}$ precipitates provided the maximum strengthening effect (peak aging) in T6, leading to the highest microhardness being measured for T6, as shown in Figure 8. In addition, there were also a number of small $Q^{\prime}$ precipitates $(\sim 5 \mathrm{~nm}$ in diameter) present. Due to the presence of $\theta^{\prime}$ and $Q^{\prime}$ in samples after T5 and T6, there were two endothermic reactions (Peak $I$ and II) that occurred during the heating in the DSC runs (Figure 6b), namely the first small Peak $I$, corresponding to dissolution of a limited amount of $Q^{\prime}$, and the second, large Peak II corresponding to the dissolution of a large amount of $\theta^{\prime}$. After T7 (Figure 9c), a larger amount of lath-like precipitates were observed, which were identified as principal $\theta^{\prime}$ precipitates by the clear spots in the SADP shown in Figure 9e [27,29,37], indicating the full precipitation in T7, which was also confirmed by its highest EC among the three tempers involving aging conditions. As the case in T6, a number of small round or granular $Q^{\prime}$ precipitates $(\sim 5 \mathrm{~nm}$ in diameter) also co-existed in the microstructure of sample after the T7 $[34,35]$. This coincides with the DSC curve of the T7 (Figure 6b), in which the first two peaks (Peaks $I$ and $I I$ ) correspond to the endothermic reactions of the dissolution of $Q^{\prime}$ and $\theta^{\prime}$, respectively, and only one exothermic peak $d$ was detected, corresponding to the precipitation of $\theta$. On the other hand, due to the larger size of the $\theta^{\prime}$ precipitates in T7 in comparison to those in T6, its strengthening effect was obviously reduced. As shown in Figure 8, the microhardness of the T7 sample was $124 \mathrm{HV}$, which is considerably lower than that of the T6 sample (142 HV).

\subsection{Al-Mg-Si AA6082 Extrusion Alloy}

The Al-Mg-Si AA6082 alloy is one of most commonly used wrought aluminum alloys in the construction and automobile industries. Figure 10 shows the DSC heating curves of extruded AA6082 alloy undergone to various treatments.

As shown in Figure 10a, the DSC curves of samples after the F (as-extruded) and SHT exhibit four exothermic peaks, located at temperatures of $\sim 160,240,320$, and $410^{\circ} \mathrm{C}$, respectively corresponding to the precipitations of GP zone (Peak $b$ ), $\beta^{\prime \prime}$ (Peak $c$ ), $\beta^{\prime}$ (Peak $d$ ), and $\beta$ (Peak $e$ ) $[3,7,38,39]$. There is also one endothermic peak (Peak $I$ ) located at $\sim 470^{\circ} \mathrm{C}$, which is related to the dissolution of $\beta$ precipitates [38,39]. In addition, one small exothermic peak, $a^{\prime}$, was detected at $\sim 10{ }^{\circ} \mathrm{C}$ in the curve of the sample after SHT treatment, which corresponds to the formation of $\mathrm{Mg} / \mathrm{Si}$ clusters during the DSC heating after solution treatment [3,7]. In the T4 temper (natural aging for 1, 7, and 28 days), three exothermic peaks $\left(c, d\right.$, and $e$ ), located at temperatures of 240,320 , and $430{ }^{\circ} \mathrm{C}$, respectively, and one endothermic peak $I$ located at $470{ }^{\circ} \mathrm{C}$ were detected (Figure $10 \mathrm{~b}$ ), which correspond to the precipitations of $\beta^{\prime \prime}, \beta^{\prime}$, and $\beta$, and the dissolution of $\beta$, respectively $[3,7,38,39]$. Figure 10c shows the DSC curves of the samples subjected to artificial aging conditions ( $\mathrm{T} 5$ and $\mathrm{T} 6$ ). As with the curve of the $\mathrm{T} 4$ samples shown in Figure 10b, there were also three exothermic peaks and one endothermic peak detected, which are related to the precipitation of $\beta^{\prime \prime}, \beta^{\prime}$, and $\beta$, and the dissolution of $\beta[3,7,38,39]$. The positions of the peaks are similar to the positions of those in Figure 10a, b, but the size of the peaks varied with the tempers (Table 5).

As with the case of the AlSi10Mg0.3Mn and 319 alloys, the number and area of exothermic peaks (marked in bold in Table 5) can be used as a first step in distinguishing between the different tempers of the AA6082 extrusion alloy. For F and SHT conditions, the most obvious difference from the aged conditions (T4, T5, and T6) was in the number of exothermal peaks in the DSC curves. As shown in Figure 10 and Table 5, the F sample exhibited four exothermal peaks and the SHT sample exhibited five, while the aged conditions generally exhibited three peaks. Between the F and SHT conditions, the smaller Peak $c$ but relatively larger Peak $e$ after SHT treatment (Table 5) in comparison to those in the $\mathrm{F}$ condition can also be used to further differentiate the tempers. For the T4 conditions, the area of Peak $c$ decreased while the area of Peak $d$ increased with increasing natural aging time. As shown 
in Table 5, upon prolonging the aging time from 1 to 28 days, the area of Peak $c$ decreased from 6.5 to $4.9 \mathrm{~J} / \mathrm{g}$, while the area of Peak $d$ increased from 1.4 to $2.5 \mathrm{~J} / \mathrm{g}$. The principal difference between the T5/T6 and T4 treatments is the much smaller areas of Peak $c$ in T5/T6. For instance, the areas of Peak $c$ in T5 and T6 were 0.8 and $0.2 \mathrm{~J} / \mathrm{g}$, respectively, which are much smaller than those in T4 (6.5 J/g in T4_1 and $4.9 \mathrm{~J} / \mathrm{g}$ in T4_28). On the other hand, T5 exhibited a larger Peak $c$ and smaller Peak $d$ in comparison to those of T6, making these tempers easily distinguishable.
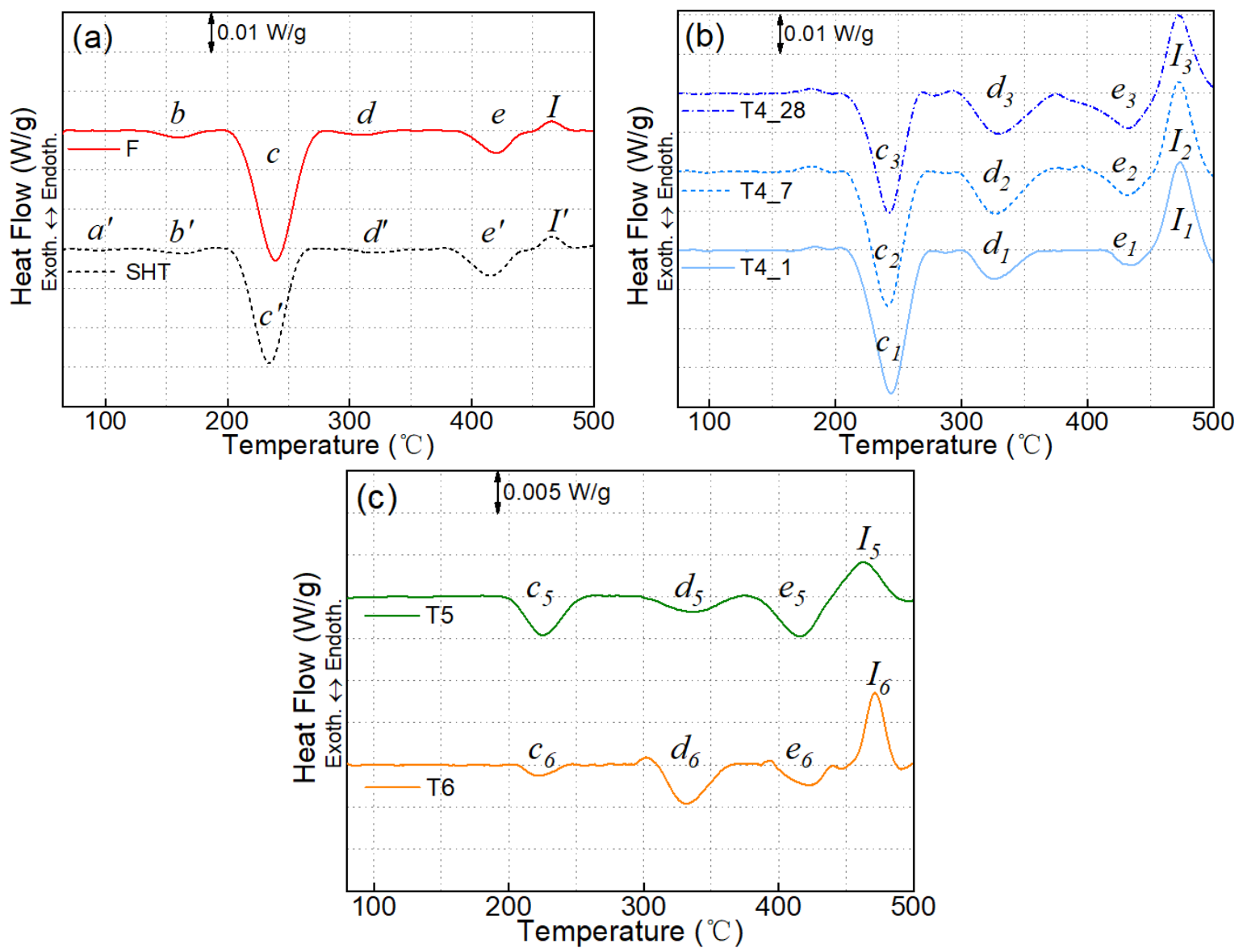

Figure 10. DSC heating curves of Al-Mg-Si AA6082 alloy subjected to (a) F and SHT, (b) T4, and (c) T5 and $\mathrm{T} 6$ treatments.

Table 5. Summary of DSC characterizations of the Al-Mg-Si AA6082 alloy.

\begin{tabular}{|c|c|c|c|c|c|c|}
\hline Temper & Exo. Peak $a$ & $\begin{array}{l}\text { Exo. Peak } b \\
\text { Series }\end{array}$ & $\begin{array}{l}\text { Exo. Peak } c \\
\text { Series (Peak } \\
\text { Temp./Area) }\end{array}$ & $\begin{array}{l}\text { Exo. Peak } d \\
\text { Series (Peak } \\
\text { Temp./Area) }\end{array}$ & $\begin{array}{l}\text { Exo. Peak } e \\
\text { Series (Peak } \\
\text { Temp./Area) }\end{array}$ & $\begin{array}{c}\text { Endo. Peak } \\
\text { I Series }\end{array}$ \\
\hline $\mathrm{F}$ & - & & $\beta^{\prime \prime}, 240^{\circ} \mathrm{C} / 6.8$ & $\beta^{\prime}, 320^{\circ} \mathrm{C} / 0.2$ & $\beta, 410^{\circ} \mathrm{C} / 1.0$ & \\
\hline SHT & Clusters, $100^{\circ} \mathrm{C}$ & GP zones, $160^{\circ} \mathrm{C}$ & $\beta^{\prime \prime}, 240^{\circ} \mathrm{C} / 5.2$ & $\beta^{\prime}, 320^{\circ} \mathrm{C} / 0.2$ & $\beta, 410^{\circ} \mathrm{C} / 1.3$ & \\
\hline T4_1 & - & - & $\beta^{\prime \prime}, 240^{\circ} \mathrm{C} / 6.5$ & $\beta^{\prime}, 320^{\circ} \mathrm{C} / 1.4$ & $\beta, 430^{\circ} \mathrm{C} / 0.6$ & \\
\hline $\mathrm{T} 4 \_7$ & - & - & $\beta^{\prime \prime}, 240^{\circ} \mathrm{C} / 5.6$ & $\beta^{\prime}, 320^{\circ} \mathrm{C} / 2.3$ & $\beta, 430^{\circ} \mathrm{C} / 1.1$ & $\beta$ dissolute \\
\hline T4_28 & - & - & $\beta^{\prime \prime}, 240^{\circ} \mathrm{C} / 4.9$ & $\beta^{\prime}, 320^{\circ} \mathrm{C} / 2.5$ & $\beta, 430^{\circ} \mathrm{C} / 1.9$ & \\
\hline $\mathrm{T} 5$ & - & - & $\beta^{\prime \prime}, 230^{\circ} \mathrm{C} / 0.8$ & $\beta^{\prime}, 330^{\circ} \mathrm{C} / 0.4$ & $\beta, 410^{\circ} \mathrm{C} / 0.8$ & \\
\hline T6 & - & - & $\beta^{\prime \prime}, 230^{\circ} \mathrm{C} / 0.2$ & $\beta^{\prime}, 330^{\circ} \mathrm{C} / 0.8$ & $\beta, 410^{\circ} \mathrm{C} / 0.4$ & \\
\hline
\end{tabular}

The characteristics of the DSC curves were closely related to the formation and transformations of precipitates in the AA6082 alloy studied. To further confirm the precipitation reactions (exothermal peaks in the DSC curves), the EC and hardness were measured (Figure 11), and the microstructures were probed by TEM (Figure 12). Similar to the AlSi10Mg0.3Mn alloy (Section 3.1), the precipitation sequence of strengthening phases in the Al-Mg-Si 6082 alloy is in the order of supersaturated solid solution to clusters, GP zones and further gradually evolve to $\beta^{\prime \prime}, \beta^{\prime}$ and $\beta$. 
As shown in Figure 11, it was found that the EC values for the F, SHT, and T4 conditions were much lower than those of the T5 and T6 conditions, due to the high contents of supersaturated solid solution (F and SHT) or GP zones (T4) [40]. Therefore, a larger volume of $\beta^{\prime \prime}$ (larger Peak $c$ ) is expected to be firstly precipitated out than that in the T5 and T6 during the DSC heating process. On the other hand, as the GP zones were already formed during the natural aging of T4, there was no peak corresponding to GP zones detected, while it was detectable in the F and SHT conditions (Peak $b$ ). Between the different T4 conditions, with the increase in natural aging time, more clusters and GP zones formed [24], resulting in a clear increase in microhardness (Figure 11). For the artificial aging involved in the T5 and T6 treatments, the EC and microhardness of these samples were much higher than those of the T4 treatment (Figure 11), indicating a much higher level of precipitation in the former, which was further confirmed by the high volume of $\beta^{\prime \prime}$ precipitates in the aluminum matrix apparent in the TEM images (Figure 12) as well as the much higher hardness value, as indicated in Figure 11. Owing to the pre-existence of $\beta^{\prime \prime}$ in T5 and T6, the formation of $\beta^{\prime \prime}$ (Peak $c$ ) was relatively weakened during the DSC heating, leading to the smaller peak areas in the T5 and T6 conditions (Table 5). On the other hand, as shown in Figure 11, the EC and microhardness of T5 were relatively lower than those of T6, indicating less-extensive precipitation of $\beta^{\prime \prime}$ in T5 than in T6. This was confirmed by the lower number density and larger size of the $\beta^{\prime \prime}$ precipitates in T5 (Figure 12c) than in T6, further explaining the lower hardness of T5 (Figure 11). Therefore, more $\beta^{\prime \prime}$ was expected to form during further DSC heating, resulting in a relatively larger area of Peak $c$ in T5 than in T6 (Figure 10c and Table 5), due to a relatively low degree of precipitation of $\beta^{\prime \prime}$ in T5.

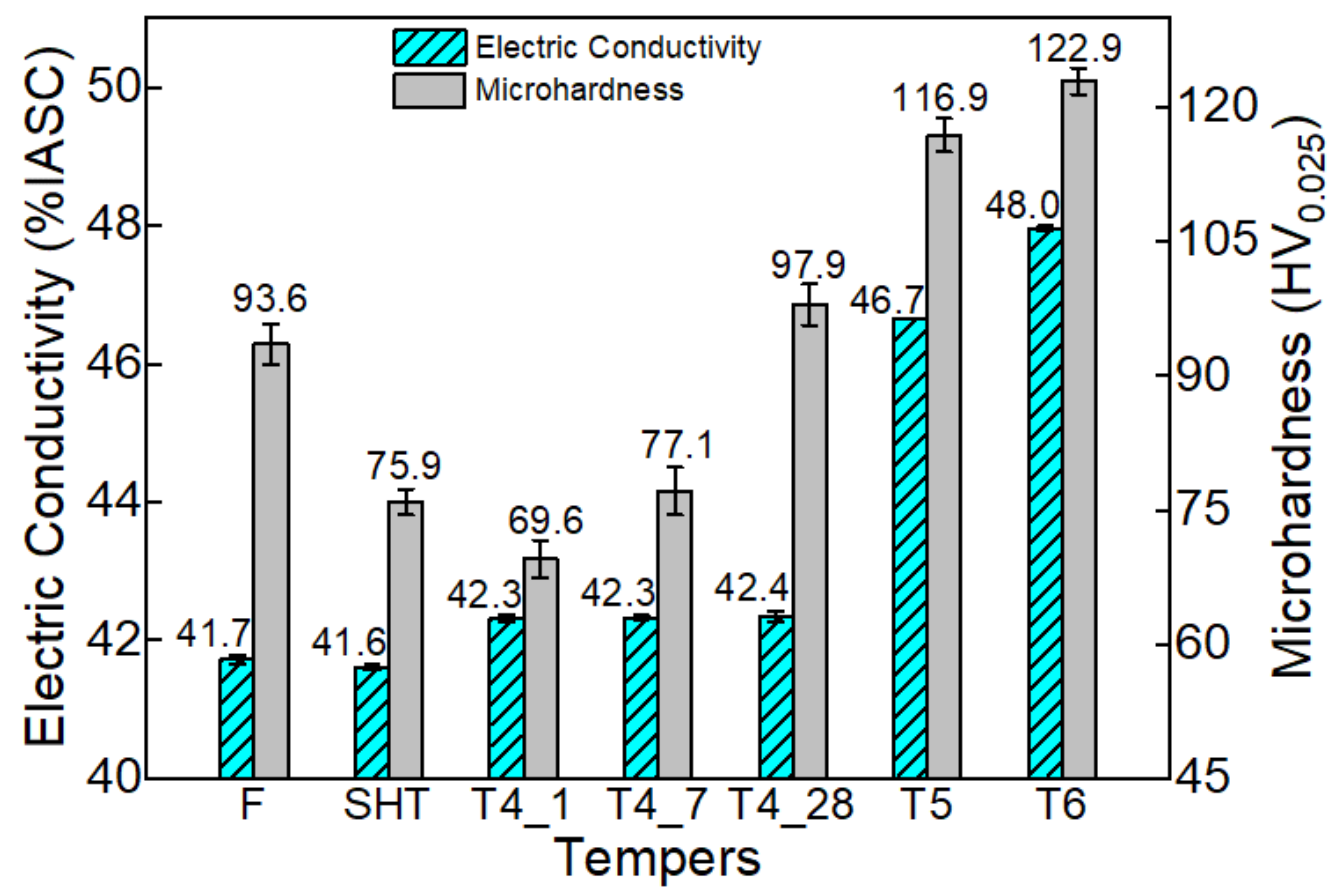

Figure 11. Evolution of EC and Vickers hardness of the Al-Mg-Si AA6082 alloys after various treatments. 


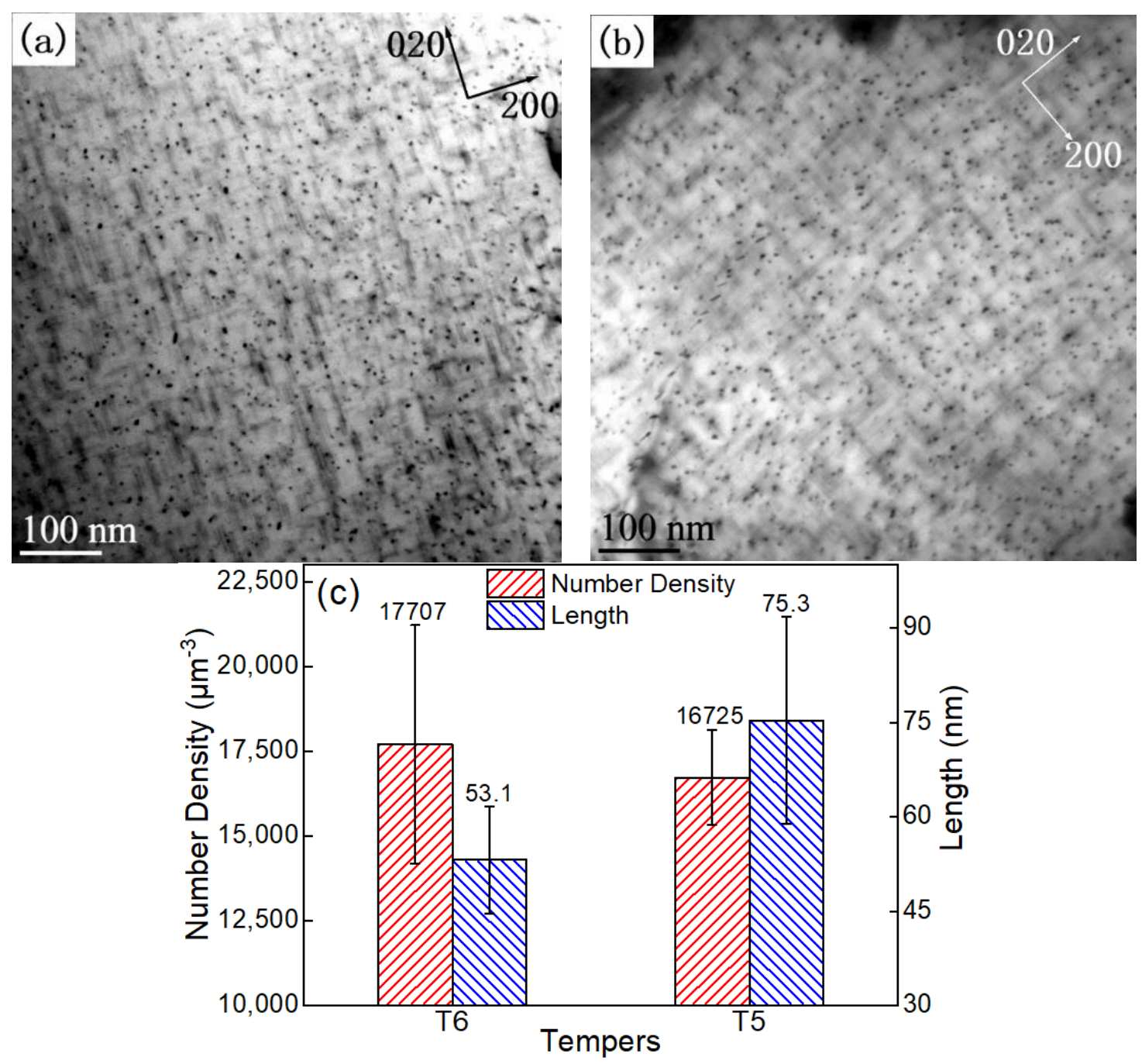

Figure 12. Precipitations after (a) T5 and (b) T6 treatments and their characteristics (c) in extruded AA6082 alloy.

\section{Summary}

In the present work, different heat-treatment tempers of three commonly used industrial aluminum alloys, namely the AlSi10Mg0.3Mn HPVDC alloy, Al-Si-Cu-Mg 319 PM alloy, and Al-Si-Mg 6082 extrusion alloy, were investigated using DSC. A number of exothermic and endothermic peaks were detected in the DSC curves, all of which were fully analyzed and characterized in consideration of the respective precipitation and dissolution reactions, aiming to establish a "fingerprint" of each temper of the three alloys studied. Results showed that the characteristics of the DSC curves, in particular the number and size of exothermic peaks, can provide an effective means of fingerprinting the various tempers. In general, the number of exothermic peaks is principally used to fingerprint the tempers with different thermal history, while the peak area is helpful to distinguish the similar tempers, such as the nature aging with different times and the artificial aging with/without solution treatment (T5 and T6). Meanwhile, the measurements of electrical conductivity and microhardness were conducted to provide the supplementary support for the DSC fingerprints. In addition, the microstructures of the samples subjected to various treatments were studied using optical microscopy and TEM to better understand the evolution of the peaks during the DSC scans.

Author Contributions: Conceptualization, K.L., F.B. and X.-G.C.; methodology, Z.C. K.L. and X.-G.C.; investigation, Z.C. and K.L.; writing-original draft preparation, Z.C. and K.L.; writing-review and editing, K.L., E.E., F.B. and X.-G.C. All authors have read and agreed to the published version of the manuscript 
Funding: This research was financial support of the Natural Sciences and Engineering Research Council of Canada (NSERC) under the Grant No. CRDPJ 514651-17.

Acknowledgments: The authors would like to acknowledge the financial support of the Natural Sciences and Engineering Research Council of Canada (NSERC) and Rio Tinto Aluminum through the Research Chair in the Metallurgy of Aluminum Transformation at University of Quebec at Chicoutimi.

Conflicts of Interest: The authors declare no conflict of interest.

\section{References}

1. Starink, M.J. Analysis of aluminium based alloys by calorimetry: Quantitative analysis of reactions and reaction kinetics. Int. Mater. Rev. 2004, 49, 191-226. [CrossRef]

2. Yassar, R.S.; Field, D.P.; Weiland, H. The effect of predeformation on the $\beta^{\prime \prime}$ and $\beta^{\prime}$ precipitates and the role of $\mathrm{Q}^{\prime}$ phase in an Al-Mg-Si alloy; AA6022. Scr. Mater. 2005, 53, 299-303. [CrossRef]

3. Chang, C.S.T.; Banhart, J. Low-temperature differential scanning calorimetry of an Al-Mg-Si alloy. Metall. Mater. Trans. A 2011, 42, 1960-1964. [CrossRef]

4. Elgallad, E.M.; Zhang, Z.; Chen, X.G. Effect of quenching rate on precipitation kinetics in AA2219 DC cast alloy. Phys. B Condens. Matter 2017, 514, 70-77. [CrossRef]

5. Wu, Y.-P.; Ye, L.-Y.; Jia, Y.-Z.; Liu, L.; Zhang, X.-M. Precipitation kinetics of 2519A aluminum alloy based on aging curves and DSC analysis. Trans. Nonferr. Met. Soc. Chin. 2014, 24, 3076-3083. [CrossRef]

6. Heugue, P.; Larouche, D.; Breton, F.; Martinez, R.; Chen, X.G. Evaluation of the growth kinetics of $\theta^{\prime}$ and $\theta-\mathrm{Al} 2 \mathrm{Cu}$ precipitates in a binary Al-3.5 Wt Pct $\mathrm{Cu}$ alloy. Metall. Mater. Trans. A 2019, 50, 3048-3060. [CrossRef]

7. Ding, L.; Jia, Z.; Zhang, Z.; Sanders, R.E.; Liu, Q.; Yang, G. The natural aging and precipitation hardening behaviour of Al-Mg-Si-Cu alloys with different $\mathrm{Mg} / \mathrm{Si}$ ratios and $\mathrm{Cu}$ additions. Mater. Sci. Eng. A 2015, 627, 119-126. [CrossRef]

8. Heugue, P.; Larouche, D.; Breton, F.; Massinon, D.; Martinez, R.; Chen, X.-G. Precipitation kinetics and evaluation of the interfacial mobility of precipitates in an AlSi7Cu3.5Mg0.15 cast alloy with $\mathrm{Zr}$ and $\mathrm{V}$ additions. Metals 2019, 9, 777. [CrossRef]

9. Ohmori, Y.; Doan, L.C.; Nakai, K. Ageing processes in Al-Mg-Si alloys during continuous heating. Mater. Trans. JIM 2002, 43, 246-255. [CrossRef]

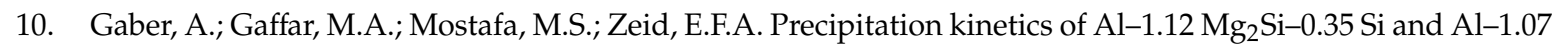
$\mathrm{Mg}_{2} \mathrm{Si}-0.33 \mathrm{Cu}$ alloys. J. Alloys Compd. 2007, 429, 167-175. [CrossRef]

11. Chen, Z.-W.; Tang, M.-J.; Zhao, K. Effect of rare earth samarium addition on the kinetics of precipitation in Al-Cu-Mn casting alloy. Int. J. Miner. Metall. Mater. 2014, 21, 155-161. [CrossRef]

12. Weng, Y.; Jia, Z.; Ding, L.; Pan, Y.; Liu, Y.; Liu, Q. Effect of Ag and Cu additions on natural aging and precipitation hardening behavior in Al-Mg-Si alloys. J. Alloys Compd. 2017, 695, 2444-2452. [CrossRef]

13. Osten, J.; Milkereit, B.; Schick, C.; Kessler, O. Dissolution and precipitation behaviour during continuous heating of Al-Mg-Si alloys in a wide range of heating rates. Materials 2015, 8, 2830-2848. [CrossRef]

14. Liu, M.; Wu, Z.; Yang, R.; Wei, J.; Yu, Y.; Skaret, P.C.; Roven, H.J. DSC analyses of static and dynamic precipitation of an Al-Mg-Si-Cu aluminum alloy. Prog. Nat. Sci. Mater. Int. 2015, 25, 153-158. [CrossRef]

15. Lloyd, D.J.; Evans, D.R.; Gupta, A.K. Precipitation reactions and the differential scanning calorimetry response of AA6111 alloy. Can. Metall. Q. 2000, 39, 475-482. [CrossRef]

16. Hemminger, W.; Sarge, S. The baseline construction and its influence on the measurement of heat with differential scanning calorimeters. J. Therm. Anal. Calorim. 1991, 37, 1455-1477. [CrossRef]

17. Andersen, S.J. Quantification of the $\mathrm{Mg}_{2} \mathrm{Si} \beta^{\prime \prime}$ and $\beta^{\prime}$ phases in AlMgSi alloys by transmission electron microscopy. Metall. Mater. Trans. A 1995, 26, 1931-1937. [CrossRef]

18. Sunde, J.K.; Paulsen, Ø.; Wenner, S.; Holmestad, R. Precipitate statistics in an Al-Mg-Si-Cu alloy from scanning precession electron diffraction data. In Proceedings of the Electron Microscopy and Analysis Group Conference 2017, Manchester, UK, 3-6 July 2017; Volume 902, p. 012022.

19. Egerton, R.F. Electron Energy-Loss Spectroscopy in the Electron Microscope; Springer Science \& Business Media: New York, NY, USA, 2011.

20. Zuo, J.; Spence, J. Electron Microdiffraction; Springer Science \& Business Media: New York, NY, USA, 2013. 
21. Dutta, I.; Allen, S. A calorimetric study of precipitation in commercial aluminium alloy 6061. J. Mater. Sci. Lett. 1991, 10, 323-326. [CrossRef]

22. Yanagihara, E.; Orii, S.; Iketani, T.; Saikawa, S.; Matsuda, K.; Ikeno, S. Precipitation structure of Al-10 mass\% $\mathrm{Si}-0.3 \mathrm{mass} \% \mathrm{Mg}$ alloy produced by high pressure die casting and permanent mold casting with $\mathrm{T} 5$ treatment. Mater. Trans. JIM 2015, 56, 1112-1119. [CrossRef]

23. Edwards, G.A.; Stiller, K.; Dunlop, G.L.; Couper, M.J. The precipitation sequence in Al-Mg-Si alloys. Acta Mater. 1998, 46, 3893-3904. [CrossRef]

24. Engler, O.; Marioara, C.D.; Aruga, Y.; Kozuka, M.; Myhr, O.R. Effect of natural ageing or pre-ageing on the evolution of precipitate structure and strength during age hardening of Al-Mg-Si alloy AA 6016. Mater. Sci. Eng. A 2019, 759, 520-529. [CrossRef]

25. Fang, X.; Song, M.; Li, K.; Du, Y. Precipitation sequence of an aged Al-Mg-Si alloy. J. Min. Metall. Sect. B 2010, 46, 171-180. [CrossRef]

26. Hwang, J.Y.; Banerjee, R.; Doty, H.W.; Kaufman, M.J. The effect of Mg on the structure and properties of Type 319 aluminum casting alloys. Acta Mater. 2009, 57, 1308-1317. [CrossRef]

27. Biswas, A.; Siegel, D.J.; Seidman, D.N. Compositional evolution of Q-phase precipitates in an aluminum alloy. Acta Mater. 2014, 75, 322-336. [CrossRef]

28. Farkoosh, A.R.; Pekguleryuz, M. Enhanced mechanical properties of an Al-Si-Cu-Mg alloy at $300{ }^{\circ} \mathrm{C}$ : Effects of Mg and the Q-precipitate phase. Mater. Sci. Eng. A 2015, 621, 277-286. [CrossRef]

29. Biswas, A.; Sen, D.; Sarkar, S.K.; Mazumder, S.; Seidman, D.N. Temporal evolution of coherent precipitates in an aluminum alloy W319: A correlative anisotropic small angle X-ray scattering, transmission electron microscopy and atom-probe tomography study. Acta Mater. 2016, 116, 219-230. [CrossRef]

30. Rodríguez-Veiga, A.; Bellón, B.; Papadimitriou, I.; Esteban-Manzanares, G.; Sabirov, I.; Llorca, J. A multidisciplinary approach to study precipitation kinetics and hardening in an $\mathrm{Al}-4 \mathrm{Cu}(w \mathrm{t}$. \%) alloy. J. Alloys Compd. 2018, 757, 504-519. [CrossRef]

31. Wang, X.; Esmaeili, S.; Lloyd, D.J. The sequence of precipitation in the Al-Mg-Si-Cu alloy AA6111. Metall. Mater. Trans. A 2006, 37, 2691-2699. [CrossRef]

32. Tavitas-Medrano, F.J.; Mohamed, A.M.A.; Gruzleski, J.E.; Samuel, F.H.; Doty, H.W. Precipitation-hardening in cast AL-Si-Cu-Mg alloys. J. Mater. Sci. 2010, 45, 641-651. [CrossRef]

33. Wang, G.; Sun, Q.; Feng, L.; Hui, L.; Jing, C. Influence of Cu content on ageing behavior of AlSiMgCu cast alloys. Mater. Des. 2007, 28, 1001-1005. [CrossRef]

34. Zheng, Y.; Xiao, W.; Ge, S.; Zhao, W.; Hanada, S.; Ma, C. Effects of Cu content and Cu/Mg ratio on the microstructure and mechanical properties of Al-Si-Cu-Mg alloys. J. Alloys Compd. 2015, 649, $291-296$. [CrossRef]

35. Xiao, Q.; Liu, H.; Yi, D.; Yin, D.; Chen, Y.; Zhang, Y.; Wang, B. Effect of Cu content on precipitation and age-hardening behavior in Al-Mg-Si-xCu alloys. J. Alloys Compd. 2017, 695, 1005-1013. [CrossRef]

36. Zuiko, I.; Kaibyshev, R. Aging behavior of an Al-Cu-Mg alloy. J. Alloys Compd. 2018, 759, 108-119. [CrossRef]

37. Shen, Z.; Ding, Q.; Liu, C.; Wang, J.; Tian, H.; Li, J.; Zhang, Z. Atomic-scale mechanism of the $\theta^{\prime \prime} \rightarrow \theta^{\prime}$ phase transformation in Al-Cu alloys. J. Mater. Sci. Technol. 2017, 33, 1159-1164. [CrossRef]

38. Zhen, L.; Kang, S.B.; Kim, H.W. Effect of natural aging and preaging on subsequent precipitation process of an Al-Mg-Si alloy with high excess silicon. Mater. Sci. Technol. 1997, 13, 905-911. [CrossRef]

39. Zhen, L.; Kang, S.B. DSC analyses of the precipitation behavior of two Al-Mg-Si alloys naturally aged for different times. Mater. Lett. 1998, 37, 349-353. [CrossRef]

40. Mondolfo, L.F. Aluminum Alloys: Structure and Properties; Elsevier: Amsterdam, The Netherlands, 2013.

(C) 2020 by the authors. Licensee MDPI, Basel, Switzerland. This article is an open access article distributed under the terms and conditions of the Creative Commons Attribution (CC BY) license (http://creativecommons.org/licenses/by/4.0/). 